\title{
Direct reprogramming of mouse fibroblasts into cardiomyocytes with chemical cocktails
}

\author{
Yanbin $\mathrm{Fu}^{1, *}$, Chenwen Huang ${ }^{1, *}$, Xinxiu $\mathrm{Xu}^{2, *}$, Haifeng $\mathrm{Gu}^{2}$, Youqiong $\mathrm{Ye}^{1}$, Cizhong Jiang ${ }^{1}$, Zilong Qiu ${ }^{3}$, \\ $\mathrm{Xin} \mathrm{Xie}^{1,2}$ \\ ${ }^{I}$ Shanghai Key Laboratory of Signaling and Disease Research, Laboratory of Receptor-based Bio-medicine, School of Life Scienc- \\ es and Technology, Tongji University, Shanghai 200092, China, ${ }^{2}$ CAS Key Laboratory of Receptor Research, the National Center \\ for Drug Screening, Shanghai Institute of Materia Medica, Chinese Academy of Sciences, Shanghai 201203, China; ${ }^{3}$ Institute of \\ Neuroscience, Key Laboratory of Primate Neurobiology, CAS Center for Excellence in Brain Science, Shanghai Institutes for Bio- \\ logical Sciences, Chinese Academy of Sciences, Shanghai 200031, China
}

The direct conversion, or transdifferentiation, of non-cardiac cells into cardiomyocytes by forced expression of transcription factors and microRNAs provides promising approaches for cardiac regeneration. However, genetic manipulations raise safety concerns and are thus not desirable in most clinical applications. The discovery of full chemically induced pluripotent stem cells suggest the possibility of replacing transcription factors with chemical cocktails. Here, we report the generation of automatically beating cardiomyocyte-like cells from mouse fibroblasts using only chemical cocktails. These chemical-induced cardiomyocyte-like cells (CiCMs) express cardiomyocyte-specific markers, exhibit sarcomeric organization, and possess typical cardiac calcium flux and electrophysiological features. Genetic lineage tracing confirms the fibroblast origin of these CiCMs. Further studies show the generation of CiCMs passes through a cardiac progenitor stage instead of a pluripotent stage. Bypassing the use of viral-derived factors, this proof of concept study lays a foundation for in vivo cardiac transdifferentiation with pharmacological agents and possibly safer treatment of heart failure.

Keywords: transdifferentiation; cardiac reprogramming; cardiomyocyte; fibroblast; chemical cocktail; small molecule compounds

Cell Research (2015) 25:1013-1024. doi:10.1038/cr.2015.99; published online 21 August 2015

\section{Introduction}

Heart failure caused by the loss or dysfunction of cardiomyocytes affects over 15 million people worldwide and is the leading cause of mortality. Although the neonatal mouse heart can regenerate after injury, the adult heart has little or no regenerative capacity [1]. The functional recovery of the heart is further hindered by the formation of fibrotic tissue after injury. So current car-

\footnotetext{
*These three authors contributed equally to this work.

Correspondence: Xin Xie

Tel: +86-21-50801313/156

E-mail: xxie@simm.ac.cn

Received 21 July 2015; revised 24 July 2015; accepted 28 July 2015; published online 21 August 2015
}

diac therapies mainly focus on protecting the remaining cardiomyocytes and preventing fibrosis $[1,2]$.

Transplantation of cardiac stem/progenitor cells to improve cardiac function is theoretically plausible, but limited cell sources and possible rejection in allogeneic transplantation prevent large-scale clinical application [3]. Embryonic stem cells (ESCs) and induced pluripotent stem cells (iPSCs) both possess cardiogenic potential, but efficiency of cardiac differentiation, functional integration of converted cells, immune compatibility, and risk of tumor formation are among the challenges to be solved [4].

Recent advances in transdifferentiation technology, i.e., reprogramming of one somatic cell type into another cell type without passing through the pluripotent state offer new approaches to generate functional cardiomyocytes [5]. It has been reported that direct reprogramming of 
non-muscle cells into cardiomyocytes can be achieved in vitro and in vivo by forced expression of cardiac transcription factors, including Gata4, Mef2c, Tbx5, Hand2, etc [6-8]. A combination of microRNAs, including miR$1,-133,-208$, and -499 with known roles in regulating broad aspects of cardiac gene expression, was also found effective in inducing cardiomyocytes from fibroblasts [9]. Interestingly, researchers also found conventional reprogramming toward pluripotency by overexpression of Yamanaka factors can be diverted toward cardiogenesis in the presence of a JAK inhibitor and cardiomyocyte-favorable culture condition [10]. The same group recently reported that small molecules can enable cardiac transdifferentiation of mouse fibroblasts with only one transcription factor Oct4 without passing through the pluripotency stage [11].

Although effective in inducing cardiac transdifferentiation, viral vector-carried transcription factors are still not favorable in therapeutic application. The use of small-molecule compounds in reprogramming and transdifferentiation, which might be more amendable in clinical development, has recently been highlighted by the discovery of full chemically induced pluripotent stem cells (CiPSCs) and neural progenitor cells [12-14]. Here, we report the generation and characterization of spontaneously beating cardiomyocyte-like cells from fibroblasts with only chemical cocktails.

\section{Results}

Induction of cardiomyocyte-like beating cells from fibroblasts by chemical cocktail

To avoid genetic insertion and carcinogenicity of the iPSCs generated by viral-based methods, Hou et al. developed a full chemical induction of CiPSCs from mouse embryonic fibroblasts (MEFs) with a small-molecule combination CRFVPTZ (C, CHIR99021; R, RepSox; F, Forskolin; V, VPA; P, Parnate; T, TTNPB; and Z, DZnep) [12]. In an attempt to repeat the generation of CiPSCs, we unexpectedly observed spontaneously contracting cells or cell clusters resembling cardiomyocytes (Supplementary information, Figure S1A and Movie S1). The beating cells or clusters could be found as early as day 6-8 after the addition of chemical cocktail CRFVPT, which is much earlier than the reported earliest date of the appearance of CiPSCs (day 20). But in this CiPSC induction condition, the beating cells or clusters were scarce, and most of them could no longer be observed after approximately one week.

A two-stage optimization strategy was carried out to improve the induction efficiency and stabilize the cardiomyocyte-like spontaneously contracting cells (Fig- ure 1A). We first optimized the cardiac reprogramming medium (CRM) used in the first stage of the induction with CRFVPT. We found bFGF, which is essential in CiPSC induction, was dispensable for the generation of contracting cells. In fact, bFGF even reduced vitamin $\mathrm{C}$-stimulated cardiac transdifferentiation (Supplementary information, Figure S1B). The combination of $15 \%$ fetal bovine serum (FBS) and 5\% knockout serum replacement (KSR) was found to be more effective in inducing beating cells than the original 10\% FBS and 10\% KSR combination used in CiPSC induction. The addition of $\mathrm{N} 2$ and B27 further increased the generation of beating clusters (Supplementary information, Figure S1C). The matrix microstructures have also been reported to play a role in cardiac reprogramming [15]. We tested different extracellular matrix gels and found that BD Matrigel-coated dishes were better than gelatin-coated or uncoated dishes (Supplementary information, Figure S1D). More beating colonies instead of single beating cells could be found after these optimizations. We then optimized the cardiomyocyte-maintaining medium (CMM) used in the second stage (after day 16) of the induction. Exposure to the cocktail CRFVPT beyond day 16 did not further improve the efficiency (Supplementary information, Figure S1E and S1F); we thus removed CRFVPT from the CMM. In contrast, 2i (CHIR99021 and PD0325901), LIF, and insulin, which have been reported to benefit the maintenance of cardiomyocytes in vitro [16-18], were found to be very effective in increasing the number of beating clusters (Supplementary information, Figure S1F). BMP4, which has been reported to be beneficial for cardiomyocyte induction [19], did not further enhance the effect of $2 i$ and LIF (Supplementary information, Figure S1F).

The final optimized protocol is described in Materials and Methods section and summarized in Figure 1A. Chemically induced cardiomyocyte-like cells (CiCMs) from MEFs displayed various morphologies: cell patches and single cells with spindle shape, rod shape or round shape (Figure 1B and Supplementary information, Movie S2). A time-dependent increase in the number of beating clusters could be observed (Figure 1C). We next determined the small molecule in the CRFVPT cocktail critical in inducing CiCMs by removing only one compound from the CRFVPT set. Combinations lacking RepSox failed to induce any beating clusters, while removing CHIR99021, or Forskolin, or VPA significantly reduced the number of beating clusters, whereas subtracting Parnate or TTNPB only slightly reduced the beating clusters (Figure 1D). These results suggested that C, R, F and V were most critical for the induction of beating clusters and indeed, the CRFV cocktail was sufficient to generate 
A

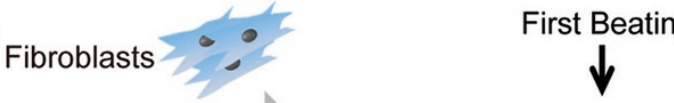

(Matrigel) First Stage: CRM + small molecule cocktails

day $\begin{array}{ll}-1 & 0\end{array}$

$\begin{array}{ll}6 & 8\end{array}$
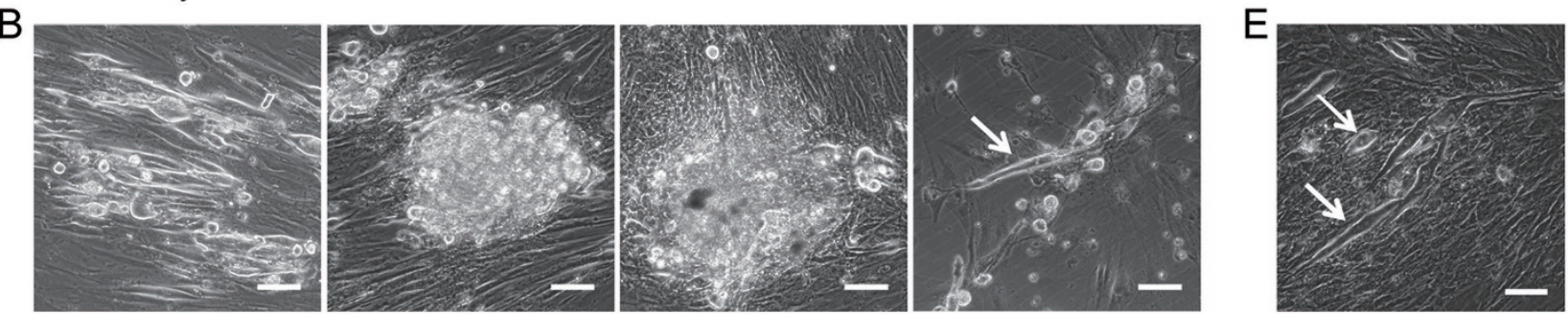

C

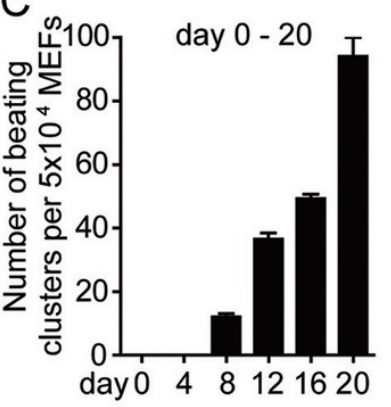

D

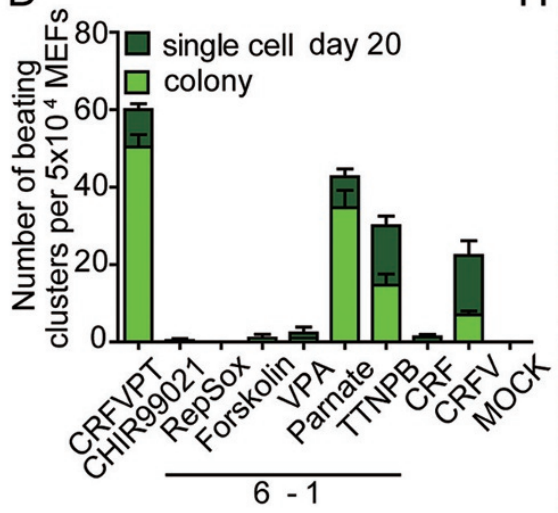

F

G
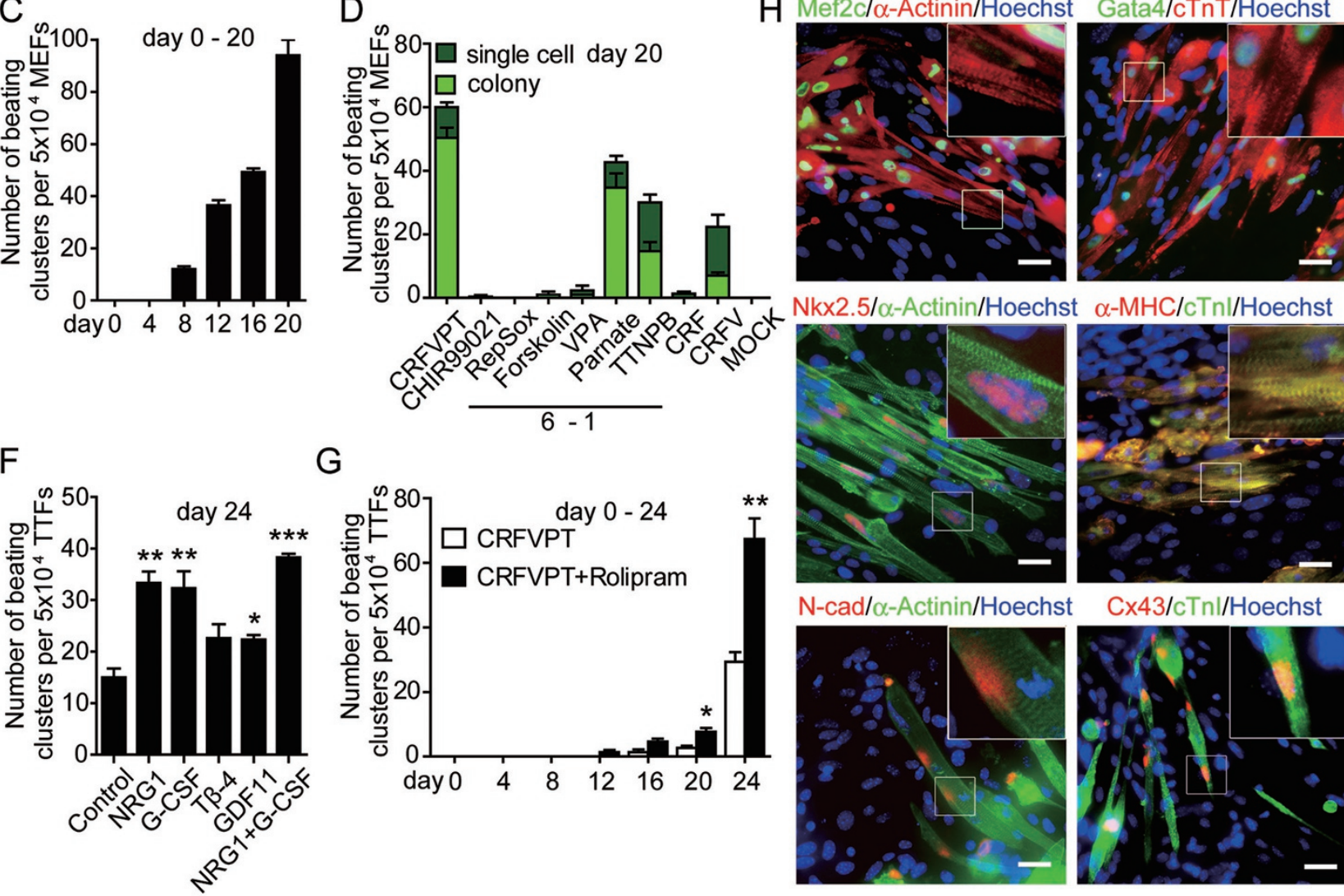

Nkx2.5/ $\alpha$-Actinin/Hoechst $\alpha-M H C / c T n l / H o e c h s t$
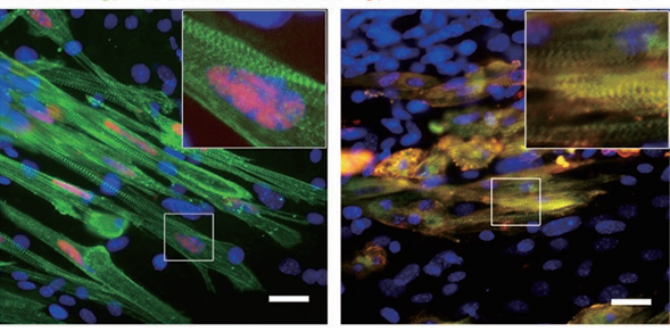

$\mathrm{N}$-cad/ $\alpha$-Actinin/Hoechst

Cx43/cTnl/Hoechst
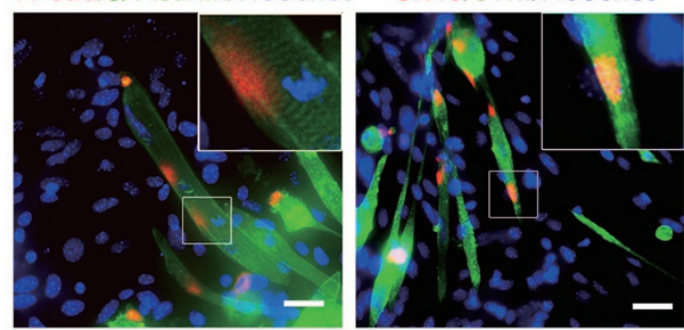

Figure 1 Fibroblasts can be directly reprogrammed to spontaneously contracting patches with chemical cocktails. (A) The scheme of direct cardiac reprogramming with small molecule cocktails. Fibroblasts were plated in fibroblast growth medium for one day and then the medium was changed into cardiac reprogramming medium (CRM) containing the small molecule cocktails (first stage). At day 16, the medium was changed into cardiomyocyte maintaining medium (CMM, second stage). The first beating clusters could be observed on day 6-8. (B) Representative morphologies of various MEF-derived beating clusters induced by the small molecule cocktail CRFVPT. See also Supplementary information, Movie S2. (C) Number of the beating clusters induced from MEFs with CRFVPT at various time points. Results are presented as means \pm SEM, $n=3$. (D) Screening for compounds essential for cardiomyocyte induction. Numbers of beating clusters at day 20 are shown. (E) Morphology of TTF-derived beating cells by small molecule cocktail CRFVPT at day 14. See also Supplementary information, Movie S3. (F) Induction of TTF-derived beating cells with CMM at the second stage supplemented with various growth factors (NRG1, $100 \mathrm{ng} / \mathrm{ml}$; G-CSF, $20 \mathrm{ng} / \mathrm{ml}$; T $\beta-4,100 \mathrm{ng} / \mathrm{ml}$; GDF11, $100 \mathrm{ng} / \mathrm{ml}$ ). (G) Induction of TTF-derived beating cells with CRFVPT plus Rolipram $(3 \mu \mathrm{M})$ in the first stage, and the growth factors $(100 \mathrm{ng} / \mathrm{ml} \mathrm{NRG}-1$ and $20 \mathrm{ng} / \mathrm{ml} \mathrm{G-CSF})$ in the second stage. Data are means \pm SEM, $n=3$. ${ }^{*} P<0.05$; ${ }^{* *} P<0.01$; ${ }^{* *} P<0.001$. (H) Immunostaining of cardiac markers Mef2c, Gata4, Nkx2.5, $\alpha-\mathrm{MHC}, \alpha$-actinin, cTnT, cTnl, N-cad, and Cx43 in beating clusters generated from MEFs on day 24 . Nuclei were stained with Hoechst. Scale bars represent $50 \mu \mathrm{m}$ in B and E, $20 \mu \mathrm{m}$ in $\mathbf{H}$. 
beating clusters (Figure 1D). A few beating cells could also be found using the CRF cocktail (Figure 1D), although the efficiency was very low. We then used CRFV as the basal induction system and screened a dozen chemicals, including modulators of pathways affecting cardiac development or somatic cell reprogramming, to see whether the generation of CiCMs could be enhanced. Several chemicals, including ICARIIN, PD169316 and Rolipram were found to be effective (Supplementary information, Figure S1G). Rolipram, a phosphodiesterase (PDE) 4 inhibitor, had the best effect, so a few more PDE inhibitors were tested. Another PDE 4 inhibitor, Cilomilast, was also highly effective, while the PDE 1, 2 and 3 inhibitors were less effective, and two PDE 5 inhibitors were ineffective (Supplementary information, Figure $\mathrm{S} 1 \mathrm{H})$.

We next used neonatal mouse tail-tip fibroblasts (TTFs) as the starting cells to induce cardiac transdifferentiation. After a two-week treatment with the CRFVPT cocktail, beating cells were also found. Most TTF-derived CiCMs displayed single-spindle shape morphology (Figure 1E and Supplementary information, Movie S3), and the reprogramming efficiency from TTFs to CiCMs was lower than from MEFs (compare Figure 1F with 1C). A number of growth factors, including neuregulin1 (NRG1), G-CSF, thymosin $\beta 4$ (T $\beta-4)$, and GDF11, have been reported to support the culture and function of cardiomyocytes [20-23]. We thus added these growth factors to the CMM in the second stage of the induction to test if they could facilitate CiCM generation from TTF. Indeed, addition of NRG1 or G-CSF, or both, significantly increased the number of beating cells. However, the recently discovered anti-aging factor GDF11 [23] only had marginal effect (Figure 1F). We also tested the addition of Rolipram to the CRFVPT cocktail in the first stage of the induction, and found it significantly enhanced the reprogramming efficiency of TTFs (Figure 1G).

CiCMs express cardiomyocyte-specific markers and exhibit typical cardiac electrophysiological features

Our characterization focused on MEF- and TTF-derived CiCMs (MEF-CiCMs and TTF-CiCMs) generated with CRFVPT. Immunostaining demonstrated that these MEF-CiCMs (day 24) not only were positive for cardiomyocyte markers, including $\alpha$-actinin, cardiac troponin- $T$ (cTnT), cardiac troponin-I (cTnI) and $\alpha$-MHC (Myh6), but also displayed a clear cross-striated pattern (Figure $1 \mathrm{H})$. FACS analysis revealed that approximately $14.5 \%$ of cells were $\alpha$-actinin positive and $9 \%$ of cells were $\alpha$-MHC positive on day 24 (Supplementary information, Figure S2A). Transcription factors important for cardiac development and function, including Mef2c, Gata4, and Nkx2.5, were also highly expressed in these MEFCiCMs (Figure 1H). Connexin 43 (Cx43), a component of gap junctions, and $\mathrm{N}$-cadherin (N-cad), an anchor for myofibrils at cell-cell contacts, were also expressed (Figure $1 \mathrm{H}$ ). In contrast, markers for skeletal myotube development, such as MyoD and myogenin, were not found in these MEF-CiCMs (Supplementary information, Figure S2B). The TTF-CiCMs also expressed cardiac-specific markers including Mef2c, cTnT, Gata4, $\alpha$-MHC and $\alpha$-actinin (Supplementary information, Figure S3A).

Quantitative RT-PCR also confirmed the time-dependent increase in the expression of cardiac-specific genes, including Nkx2.5, Mef2c, Gata4, $\beta$-MHC, $c T n T$, and $R y r 2$, during the induction (Supplementary information, Figure S2C). The global gene expression patterns of MEFs, MEF-CiCMs, and cardiomyocytes were analyzed with microarrays. Compared with MEFs, 477 genes were upregulated and 276 were downregulated for more than 5 folds in MEF-CiCMs. CiCMs and cardiomyocytes showed very similar expression patterns of these genes and were thus clustered into one group (Figure 2A). Gene ontology (GO) term enrichment analysis of these genes indicated that genes involved in muscle development, myofibril assembly, muscle contraction, and especially cardiac muscle development were significantly upregulated in CiCM samples, while genes involved in cell cycle and mitosis control were significantly downregulated (Figure 2B), indicating a clear transition from dividing MEFs to differentiated cardiomyocyte-like state.

We then used Fluo-4 as an indicator to trace the calcium transients, which underlie the contraction and relaxation of spontaneously beating cardiomyocytes, in these CiCMs. In MEF-CiCMs (Figure 2C and Supplementary information, Movie S4), the peak fluorescence ratio $\left(\mathrm{F} / \mathrm{F}_{0}\right)$ in these transients was $3.2 \pm 0.4(n=$ 11), comparable to previous measurements made with neonatal or ESC-derived cardiomyocytes [24]. Normal cardiomyocytes can respond to adrenergic and muscarinic signaling and adjust their calcium transient and contractile frequency [25]. Similar phenomenon could be observed in these CiCMs. Addition of the $\beta$-adrenergic agonist isoproterenol (Iso, $1 \mu \mathrm{M}$ ) significantly increased the frequency of the spontaneous calcium transients and shortened the decay period, while treatment of carbachol $(\mathrm{Cch}, 5 \mu \mathrm{M})$, a muscarinic agonist, significantly reduced the calcium transient frequency and prolonged the decay time (Figure 2C-2E). The TTF-CiCMs also displayed similar spontaneous calcium transients (Supplementary information, Figure S3B).

To further characterize the CiCMs and rule out the possibility that they were myoblasts or smooth muscles, which could also have spontaneous calcium transients 
A

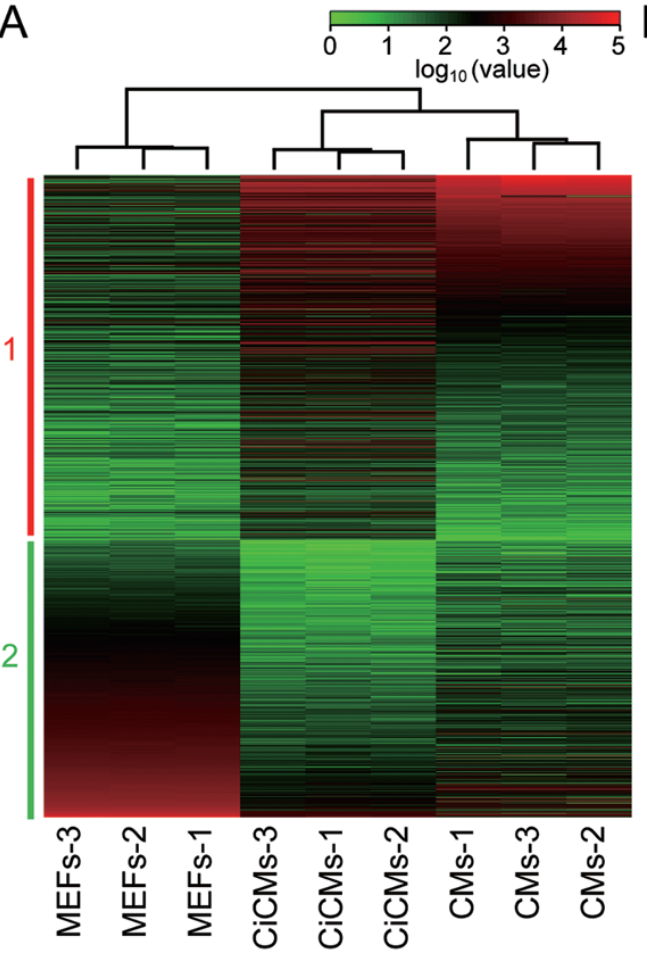

B Biological Process [- $\log _{10}(P$-value $\left.)\right]$

0

actomyosin structure organization

myofibril assembly

muscle organ development

muscle contraction

striated muscle cell development

muscle system process

striated muscle tissue development

muscle cell development

muscle tissue development

assembly involved in morphogenesis

striated muscle cell differentiation

cytoskeleton organization

muscle cell differentiation

actin filament-based process

actin cytoskeleton organization

cardiac muscle tissue development

sarcomere organization

cardiac myofibril assembly

heart development

cardiac muscle cell development

C

Basal
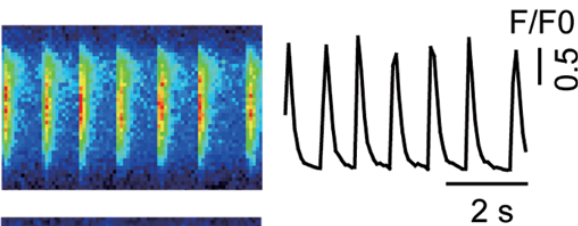

Cch
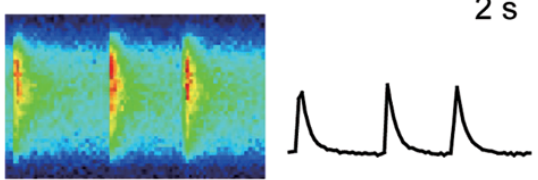

Iso
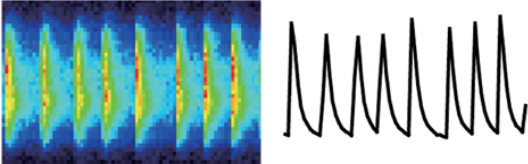

G

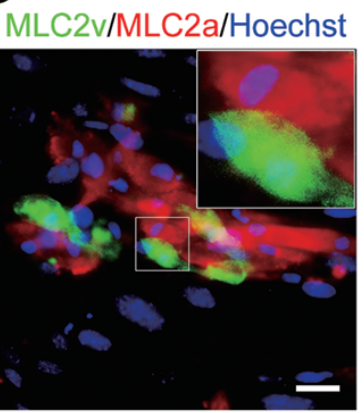

D

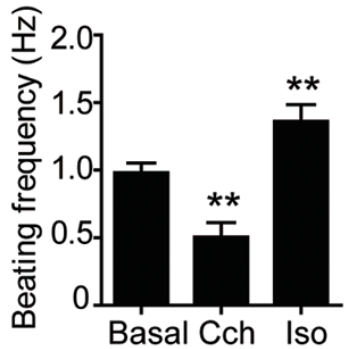

upregulated genes

Biological Process [- $\log _{10}(P$-value $\left.)\right]$

0

\begin{tabular}{|l|}
\hline mitotic cell cycle \\
\hline cell cycle phase \\
\hline M phase of mitotic cell cycle \\
\hline M phase \\
\hline cell cycle process \\
\hline nuclear division \\
\hline mitosis \\
\hline organelle fission \\
\hline cell division \\
\hline cell cycle \\
\hline extracellular matrix organization \\
\hline cell adhesion \\
\hline biological adhesion \\
\hline extracellular structure organization \\
\hline microtubule-based process \\
\hline chromosome segregation \\
\hline response to wounding \\
\hline motor axon guidance \\
\hline regulation of cell cycle \\
\hline cell cycle checkpoint \\
\hline downregulated genes \\
\hline
\end{tabular}

E

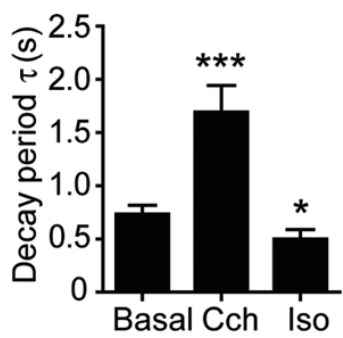

$\mathrm{F}$

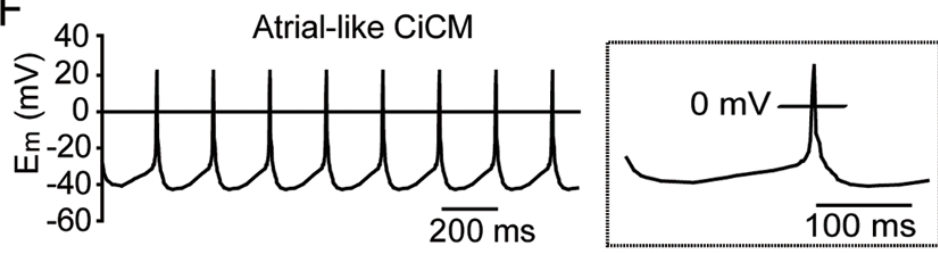

Ventricular-like CiCM

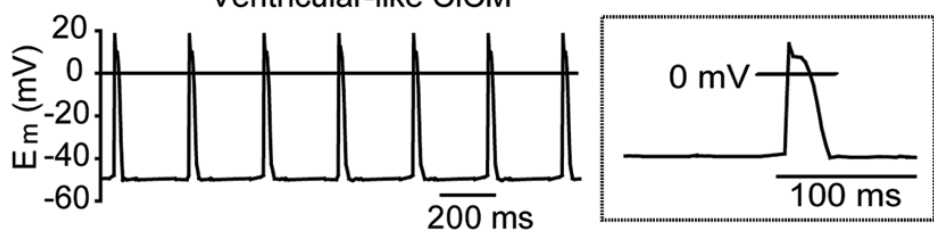

$\mathrm{H}$

\begin{tabular}{cccccccc}
\hline Cell Type & $\begin{array}{c}\mathrm{dv} / \mathrm{dtMax} \\
(\mathrm{V} / \mathrm{s})\end{array}$ & $\begin{array}{c}\text { OSP } \\
(\mathrm{mV})\end{array}$ & $\begin{array}{c}\text { MDP } \\
(\mathrm{mV})\end{array}$ & $\begin{array}{c}\text { APA } \\
(\mathrm{mV})\end{array}$ & $\begin{array}{c}\text { Freq } \\
(\mathrm{Hz})\end{array}$ & $\begin{array}{c}\text { APD50 } \\
(\mathrm{ms})\end{array}$ & $\begin{array}{c}\text { APD90 } \\
(\mathrm{ms})\end{array}$ \\
\hline A-like $(\mathrm{n}=13)$ & $33.7 \pm 3.6$ & $22.5 \pm 1.9$ & $-49.6 \pm 1.4$ & $72.1 \pm 1.0$ & $4.1 \pm 0.1$ & $33.1 \pm 5.3$ & $35.2 \pm 5.4$ \\
\hline V-like $(\mathrm{n}=4)$ & $41.5 \pm 5.5$ & $14.1 \pm 1.3$ & $-63.1 \pm 4.4$ & $77.2 \pm 4.1$ & $3.8 \pm 0.3$ & $35.9 \pm 3.8$ & $49.8 \pm 8.3$ \\
\hline
\end{tabular}


Figure 2 CiCMs exhibit typical cardiac calcium flux, electrophysiological features, and gene expression profile. (A) Heatmap illustration of microarray data from MEFs, MEF-CiCMs (beating clusters picked at day 24) and cardiomyocytes. Groups 1 and 2 contain genes that are upregulated or downregulated for $>5$ fold in CiCMs compared with MEFs. (B) GO term enrichment analysis of genes that display > 5 fold change in expression in CiCMs and cardiomyocytes compared with MEFs. Left, upregulated genes; right, downregulated genes. (C) Calcium flux in MEF-derived CiCMs at day 25 of the induction. Calcium transients were recorded at basal condition, or after $5 \mu \mathrm{M}$ carbachol (Cch) or $1 \mu \mathrm{M}$ isoproterenol (Iso) treatment. Left, linescan images of calcium transients; right, traces of calcium transients. See also Supplementary information, Movie S4. (D) Calcium transient frequency and $(\mathrm{E})$ decay rate at basal state $(n=18)$, and after treatment of Cch $(n=8)$ or Iso $(n=13)$. Data are presented as means \pm SEM. ${ }^{*} P<0.05 ;{ }^{* *} P<0.01$; ${ }^{* *} P<0.001$. (F) Representative action potentials (AP) of CiCMs induced with CRFVPT cocktail. $E_{m}$, membrane potential in millivolts. (G) Immunostaining of MLC2a, MLC2v, $\alpha$-actinin and HCN4 in MEF-derived CiCMs. Scale bars represent $20 \mu \mathrm{m}$. (H) AP parameters of CiCMs including maximum upstroke velocity (dv/ dtMax), overshoot potential (OSP), minimum diastolic potential (MDP), AP amplitude (APA), beating frequency (Freq), AP durations (APDs) at the level of $50 \%$ (APD50) and $90 \%$ repolarization (APD90). Data are means \pm SEM.

and contractility [26], we analyzed the action potentials (APs) of these CiCMs. In single-cell patch clamp assay, APs were recorded from single spontaneously beating cells around day 20 of reprogramming. Most of the MEF-CiCMs $(n=13)$ generated APs that closely resembled atrial-like APs $[10,27]$, and to a lesser extent earlier pacemaker-like APs [28], with a mean diastolic potential (MDP) of $-49.6 \mathrm{mV}$ and a mean overshoot potential (OSP) of $22.5 \mathrm{mV}$. A small portion of the MEF-CiCMs $(n=4)$ showed ventricular-like AP morphology with a MDP of $-63.1 \mathrm{mV}$ and a mean OSP of $14.1 \mathrm{mV}$ (Figure $2 \mathrm{~F}$ and $2 \mathrm{H}$ ). Consistent with the electrophysiological study, immunostaining of the MEF-CiCMs confirmed the expression of myosin light chain-2a (MLC2a), an atrial specific marker; $M L C 2 \mathrm{v}$, a ventricular specific marker, and HCN4, a pacemaker marker (Figure 2G). Both the atrial-like and ventricular-like APs could also be found in TTF-CiCMs (Supplementary information, Figure S3C).

\section{Lineage tracing of chemical-induced transdifferentiation of MEFs toward cardiomyocytes}

To ultimately confirm that the CiCMs were indeed transdifferentiated from fibroblasts but not the possible contaminating progenitor cells, we used a lineage-tracing experiment to track the origin of the CiCMs. Transgenic mice that express Cre recombinase under the control of the fibroblast specific protein-1 (Fsp1 or S100A4) promoter were crossed with the $\mathrm{R} 26 \mathrm{R}^{\text {tdTomato }}$ mice, in which the expression of tdTomato is prevented by a loxP-flanked STOP cassette. Since Fspl is specifically expressed in fibroblasts [29], the progeny of these mice (Fsp1-Cre:R26R ${ }^{\text {tdTomato }}$ ) would have the red fluorescent protein tdTomato expressed specifically in the fibroblasts (Figure 3A).

The Fsp1-Cre:R26R ${ }^{\text {tdTomato }}$ MEFs, which indeed express tdTomato, were induced for cardiac transdifferentiation with CRFVPT. Spontaneously contracting CiCMs with the expression of tdTomato could be observed in the culture (Supplementary information, Movie S5). Immunofluorescent analysis on day 24 confirmed that these tdTomato-CiCMs were positive for cardiomyocyte markers, including Mef2c, Nkx2.5, $\alpha$-actinin, cTnT, cTnI, and $\alpha-\mathrm{MHC}$, and these cells also displayed a clear cross-striated pattern (Figure 3B). Spontaneous calcium oscillations could also be observed in tdTomato-CiCMs on day 25 (Figure 3C). Single-cell patch clamp assay recorded atrial-like or ventricular-like APs from these tdTomato-CiCMs (Figure 3D-3F). These data clearly demonstrate that the CiCMs generated with chemical cocktail are indeed transdifferentiated from fibroblasts.

CiCMs are generated through a cardiac precursor-like stage but not the iPSC stage

We were intrigued by an observation that many colonies or cell patches formed before the initiation of beating, and examined if the generation of CiCMs went through an iPSC or precursor stage as previously reported in transcription factor-mediated cardiac reprogramming [10]. Quantitative RT-PCR analysis revealed that the expression of pluripotency genes such as Oct4, Sox2, Nanog, and Rex 1 remained at a very low level during the CRFVPT-mediated cardiac reprogramming (Supplementary information, Figure S2D). In contrast, cardiac markers were gradually upregulated (Supplementary information, Figure S2C). We also performed time-lapse imaging of OG2 MEFs (MEFs containing an Oct4:GFP reporter) undergoing CRFVPT-induced cardiac reprogramming (Figure 4A). Beating clusters began to appear at day 12 in this experiment, and immunocytochemical staining revealed that these beating clusters expressed $\alpha$-MHC at day 26 (Figure 4A). However, $\mathrm{GFP}^{+}$cells were never detected throughout the entire reprogramming process. This is in clear contrast to Yamanaka factor (Oct4, Klf4, Sox2, and cMyc)-mediated reprogramming, in which $\mathrm{GFP}^{+}$iPSC colonies can be observed at day 12 (Figure $4 \mathrm{~A})$. These data indicate that chemical-mediated cardiac 

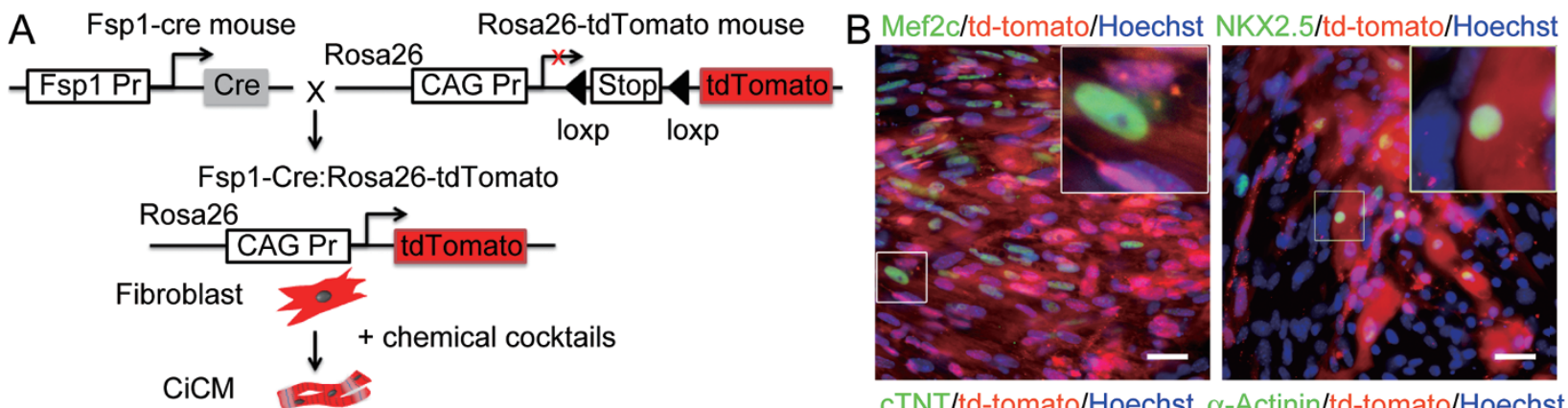

C
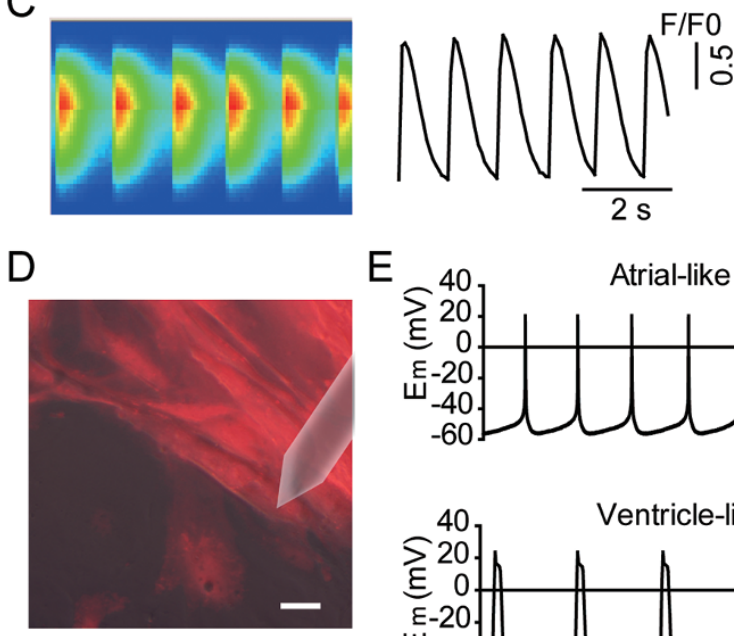

$\mathrm{E}$
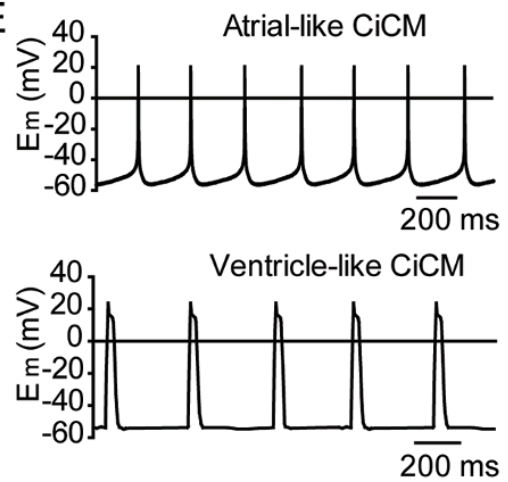

cTNT/td-tomato/Hoechst $\alpha$-Actinin/td-tomato/Hoechst
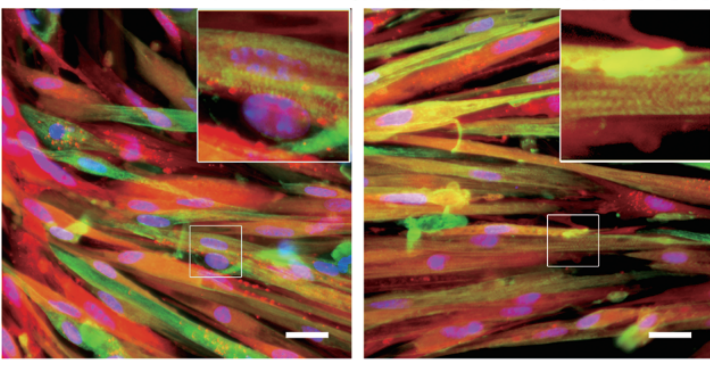

cTNI/td-tomato/Hoechst $\alpha-M H C /$ td-tomato/Hoechst
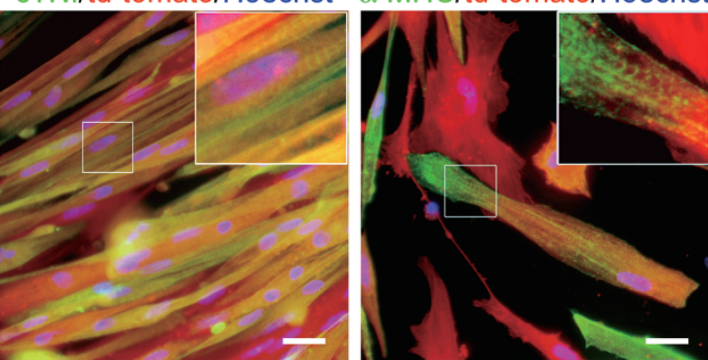

$\mathrm{F}$

\begin{tabular}{cccccccc}
\hline Cell Type & $\begin{array}{c}\text { dv/dtMax } \\
(\mathrm{V} / \mathrm{s})\end{array}$ & $\begin{array}{c}\text { OSP } \\
(\mathrm{mV})\end{array}$ & $\begin{array}{c}\text { MDP } \\
(\mathrm{mV})\end{array}$ & $\begin{array}{c}\text { APA } \\
(\mathrm{mV})\end{array}$ & $\begin{array}{c}\text { Freq } \\
(\mathrm{Hz})\end{array}$ & $\begin{array}{c}\text { APD50 } \\
(\mathrm{ms})\end{array}$ & $\begin{array}{c}\text { APD90 } \\
(\mathrm{ms})\end{array}$ \\
\hline A-like $(\mathrm{n}=5)$ & $35.1 \pm 1.4$ & $23.7 \pm 1.5$ & $-53.4 \pm 2.1$ & $81.9 \pm 0.6$ & $3.3 \pm 0.2$ & $33.2 \pm 1.7$ & $36.9 \pm 2.3$ \\
\hline V-like $(\mathrm{n}=4)$ & $66.7 \pm 1.8$ & $22.1 \pm 0.6$ & $-55.1 \pm 0.3$ & $77.2 \pm 1.6$ & $2.7 \pm 0.1$ & $38.8 \pm 1.0$ & $46.5 \pm 1.0$ \\
\hline
\end{tabular}

Figure 3 Lineage tracing of chemical induced transdifferentiation of MEFs toward cardiomyocytes. (A) Schematic diagram of the genetic fate mapping method used to trace the origin of CiCMs reprogrammed from Fsp1-Cre:R26R ${ }^{\text {tdTomato }}$ MEFs. (B) Co-localization of tdTomato (red) with various cardiac markers, including Mef2c, NKX2.5, $\alpha$-actinin, cTnT, cTnl and $\alpha$-MHC in beating clusters generated from Fsp1-Cre:R26R ${ }^{\text {tdTomato }}$ MEFs on day 24 with chemical cocktail CRFVPT. Nuclei are stained with Hoechst. (C) Spontaneous calcium transients in the tdTomato-CiCMs at day 25 of induction. Left, linescan images; right, traces of calcium signals. (D) A representative tdTomato-CiCM used for electrophysiological characterization. (E) Representative action potentials (AP) of tdTomato-CiCM. (F) AP parameters of tdTomato-CiCMs. Data are means \pm SEM. Scale bars in B and $\mathbf{D}$ represent $20 \mu \mathrm{m}$.

reprogramming does not transverse an iPSC state.

A cardiac precursor stage is necessary for normal cardiomyocyte development [30]. Previous report also described a cardiac precursor stage in transcription factor-mediated generation of cardiomyocyte-like cells [10]. We also found that the expression of several cardiac precursor markers, including Sca-1, Abcg2, Wt1, Flk1, and Mesp1 [31, 32], was upregulated during the early phase (typically day 8-20) of chemical-induced cardiac reprogramming, and was gradually downregulated at late stage (after day 24; Figure 4B). Sca- $1^{+}$cardiac precursor-like cells could be readily detected in the CRFVPT-induced cardiac reprogramming system at day 20 (Figure 4C). As the cardiac precursors are able to differentiate into smooth muscle cells and endothelial cells during embryonic development [33], we continued to culture the Sca- 

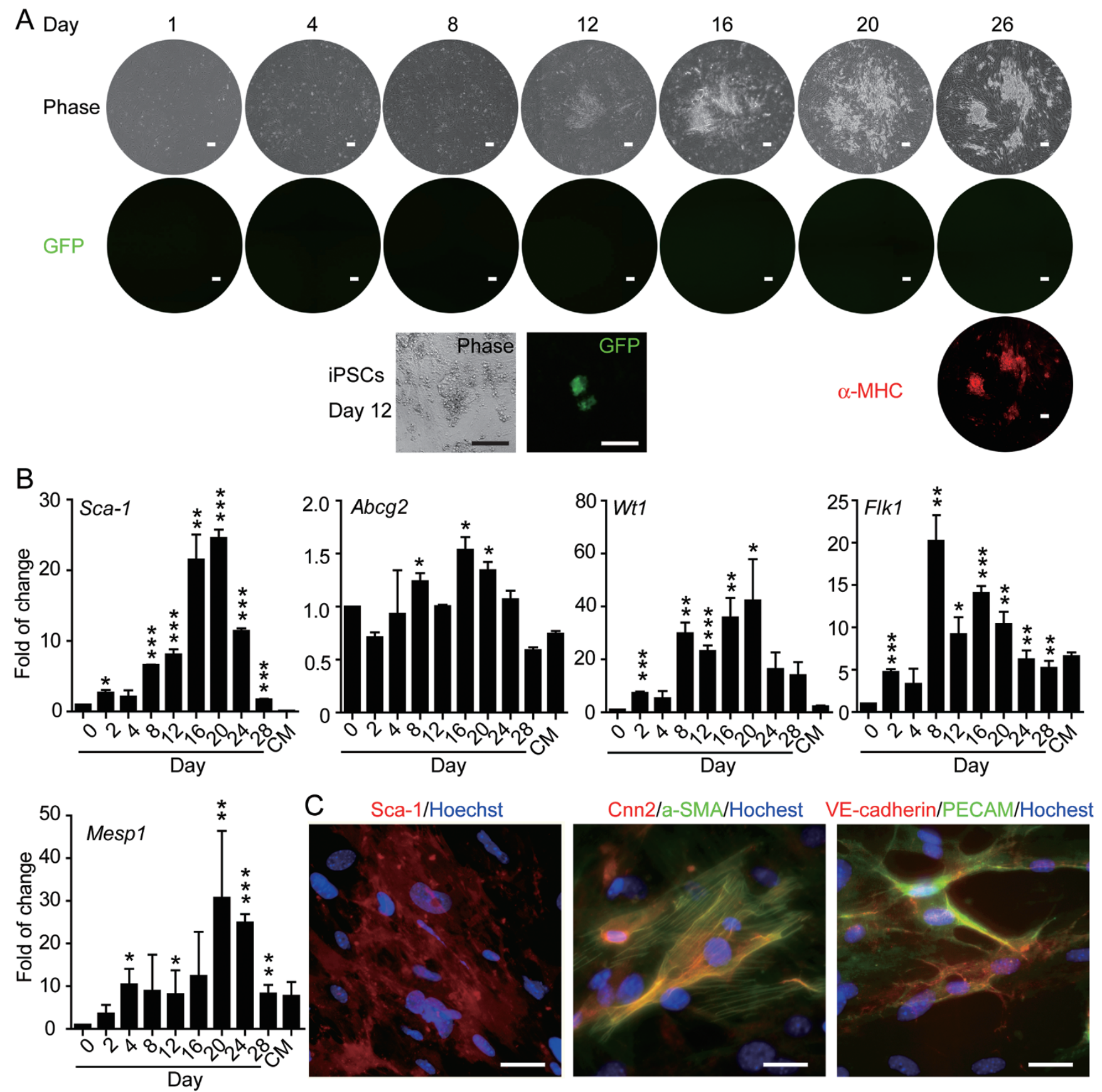

Cnn2/a-SMA/Hochest VE-cadherin/PECAM/Hochest

D

CiPSCs
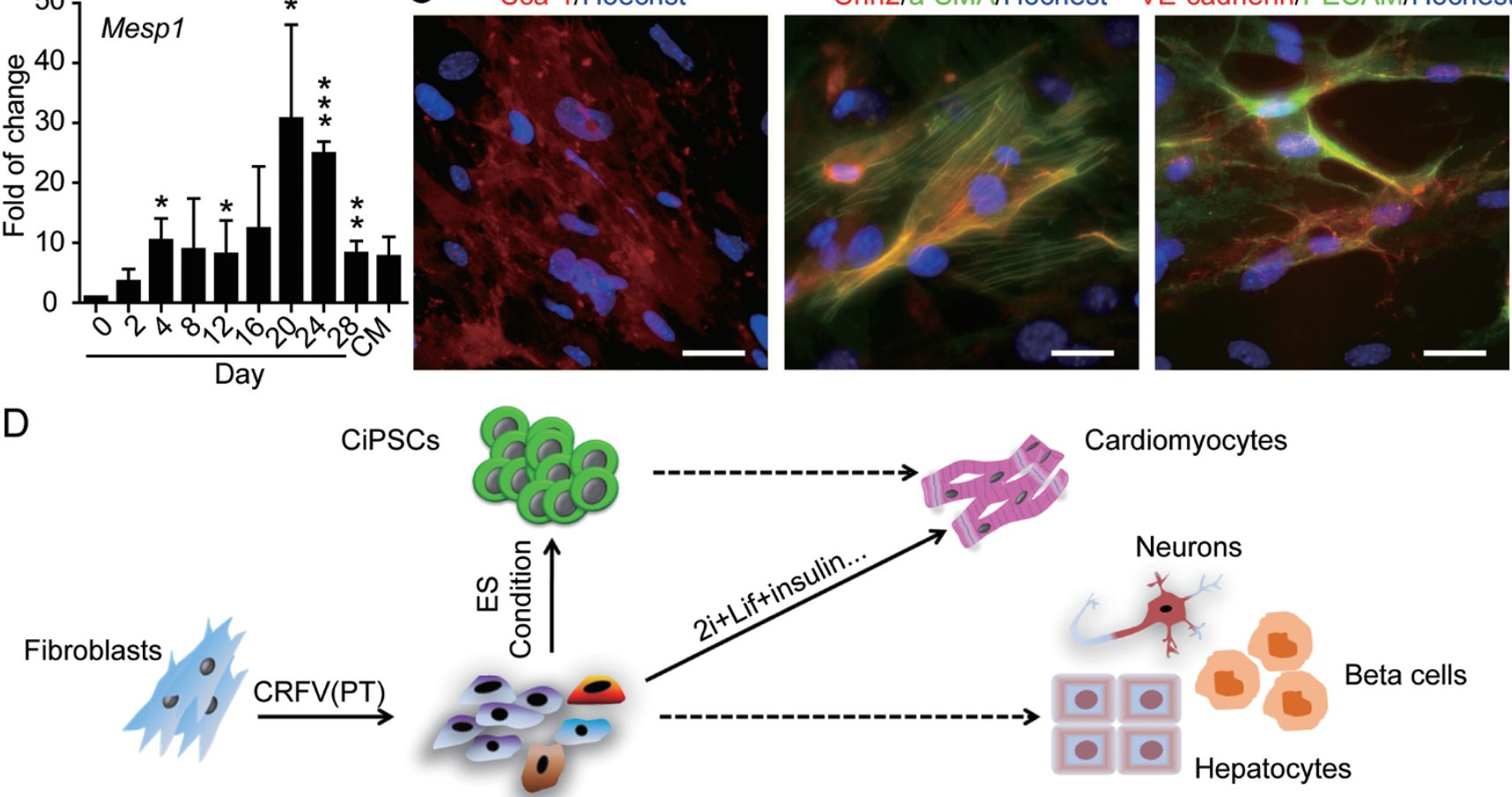

Mixed progenitor cells 
Figure 4 CiCMs were generated through cardiac precursor stage but not via iPSCs. (A) Time-lapse images of CiCMs generated from OG2 MEFs carrying an Oct4::GFP reporter (upper panels, phase and GFP). $\alpha$-MHC (Red) was stained at day 26. Lower panel show iPSCs cells $\left(\mathrm{GFP}^{+}\right)$at day 12 after induction with Yamanaka factors (Oct4, Sox2, cMyc, and Klf4). (B) Expression of cardiac precursor markers: Sca-1, Abcg2, Wt1, Flk1, and Mesp1 by quantitative RT-PCR during CiCMs induction. Data are means \pm SEM, $n=3$. ${ }^{*} P<0.05,{ }^{* *} P<0.01$, ${ }^{* * *} P<0.001$, versus MEFs (day 0 ). (C) Sca- $1^{+}$cells at day 20 of induction (left panel). Continuous culture of Sca- $1^{+}$cells in either smooth muscle cell differentiation medium or endothelial cell differentiation medium for another two weeks produced $\alpha$-SMA and Cnn2 positive cells (middle panel), or PECAM and VE-cadherin positive cells (right panel), respectively. Scale bars represent $200 \mu \mathrm{m}$ in A and $20 \mu \mathrm{m}$ in C. (D) A model for direct reprogramming of MEFs into cardiomyocytes with chemicals. Chemical combination might induce the generation of a mixed progenitor (or unstable intermediate) population. With favorable culture conditions, these progenitor/intermediate cells might be induced to become pluripotent or develop into various functional cells.

$1^{+}$cardiac precursor-like cells in differentiation conditions that favor the generation and maintenance of either endothelial or smooth muscle cells. As demonstrated in Figure $4 \mathrm{C}$, the $\alpha$-SMA/Cnn $2^{+}$and the PECAM/VE-cadherin $^{+}$cells could be observed in culture conditions favoring smooth muscle cells and endothelial cells, respectively. These data show that the generation of CiCMs goes through a cardiac precursor-like stage, somewhat resembling the natural development of cardiomyocytes.

\section{Discussion}

Here, we present the first evidence of chemical-mediated direct conversion of fibroblasts into the cardiomyocyte lineage, and the resulting spontaneously contracting cells are named CiCMs. Previous investigations have demonstrated that cardiomyocyte-like cells can be induced from non-cardiac cells by ectopic expression of transcription factors and microRNAs [6-9], and small molecules can facilitate single genetic factor-mediated cardiac transdifferentiation [11], the unavoidable genetic manipulations are not desirable in clinical applications. Compared with these methods, our full chemical approach is more amendable in clinical use and may induce functional cardiac transdifferentiation in vivo and avoid potential complications, including tumor formation, tissue rejection and homing ability of injected cells, in cell transplantation therapy for cardiac diseases [5].

It is interesting to note that the generation of functional CiCMs passes through a cardiac precursor-like stage, and both atrial-like and ventricular-like cells can be found in the culture. This indicates with further manipulation of the chemical cocktails and culture conditions, obtaining specific cell types within a particular lineage could be achieved. The existence of a cardiac precursor-like stage can also be capitalized for in vivo application. Cardiac progenitors may be more robust in surviving in the hostile graft environment, and they may not only restore myocardial tissue, but also contribute to revascularization of the heart [34].
The precise mechanisms underlying the chemical induction of cardiac transdifferentiation remain to be elucidated. Notably, the initial beating cells were observed unexpectedly in an attempt to repeat the generation of CiPSCs [12], although the appearance of CiCMs were much earlier (one week after induction) than the reported earliest date of CiPSC appearance (day 20). We do not fully understand why the same chemical combination CRFVPTZ could lead to both CiPSCs and CiCMs, but the later culture condition seem to play a critical role. It has been reported that the pluripotent Yamanaka factors could also be used to generate cardiomyocytes in a cardiomyocyte-favorable culture condition [10]. Similarly, Yamanaka factors have also been used to generate hepatocytes and pancreatic cells from fibroblasts [5]. Hou et al. also found that Gata4, a transcription factor used for cardiac transdifferentiation [6], was upregulated at day 12 after the treatment with chemicals [12], and their later culture conditions may favor pluripotency induction. Various morphological changes could be observed at the early stage of chemical induction (data not shown), and we thus propose that the chemical combination might induce the generation of a mixed progenitor (or unstable intermediate) population. When favorable culture conditions are provided, these progenitor/intermediate cells could be induced to become pluripotent or differentiate into various functional cells (Figure 4D).

Our optimized condition for CiCM induction is significantly different from the CiPSC condition. DZnep (Z), which is one of the four core chemicals (CRFZ) in CiP$\mathrm{SC}$ induction and crucial for the expression of Oct4 [12], was dispensable for CiCM generation. bFGF, which is critical in inducing CiPSC [12], did not facilitate CiCM induction. Our study demonstrates that the four core chemicals for CiCM induction are CRFV, with RepSox (R) being the most important, since removing $\mathrm{R}$ failed to generate any beating cell. $\mathrm{R}$ is a potent and selective inhibitor of TGF $\beta$ R-1, and CHIR99021 (C) is a GSK3 inhibitor that mimics the activation of Wnt pathway. Both Wnt signaling activation and TGF $\beta$ inhibition have 
been reported to play critical roles in promoting reprogramming, inducing cardiomyocyte differentiation and preventing myocardial fibrosis $[35,36]$. Forskolin (F) promotes the generation of intracellular cAMP and may facilitate gene expression via a CREB-dependent mechanism. The increased cAMP may also lead to PKA-mediated phosphorylation of connexins and promote electrical cell-to-cell coupling in cardiac cells [37]. Rolipram and Cilomilast, both PDE 4 inhibitors, can enhance the generation of CiCMs. PDEs are enzymes responsible for the breakdown of the second messengers with different substrate specificities: some are cAMP-selective ( $\mathrm{PDE} 4,7$, and 8); some are cGMP-selective (PDE 5, 6, and 9), and others can hydrolyze both cAMP and cGMP (PDE 1, 2, 3,10 , and 11) [38]. Our results suggest that the inhibitors of cAMP-selective PDEs may be more effective than the inhibitors of cGMP-selective PDEs (although more compounds need to be tested), indicating the importance of the intracellular cAMP level in cardiac reprogramming. VPA (V) as a HADC inhibitor may accelerate the global gene activation during transdifferentiation.

Besides chemicals, several growth factors that favor the survival or function of cardiomyocytes, including NRG1, G-CSF, GDF11, and T $\beta-4$ [20-23], can also enhance $\mathrm{CiCM}$ induction when added at the second stage. It is most surprising that GDF11, which has recently been reported to rescue cardiac functions in aged mice [23], was not effective in our experiment, possibly reflecting a difference between in vitro and in vivo conditions.

In conclusion, our chemical cocktail strategy provides a new approach for cardiomyocyte regeneration and lays the foundation for in vivo cardiac transdifferentiation using pharmacological agents and possibly safer treatment of heart failure. Future mechanistic studies based on these chemicals will also help us gain insights into the roles of the related signaling pathways in myocardial regeneration.

\section{Materials and Methods}

\section{Cell culture}

MEFs were isolated from embryonic day 13.5 (E13.5) C57BL/6 mouse embryos. The head, limbs, and internal organs were carefully removed from embryos, and then the rest tissues were cut and trypsinized into single-cell suspensions. MEFs were cultured in fibroblast growth medium consisting of DMEM (Gibco), 15\% FBS (Hyclone, 30084), $2 \mathrm{mM}$ Glutamax (Gibco), $0.1 \mathrm{mM}$ non-essential amino acids (NEAA; Gibco), 100 units/ml penicillin and $100 \mu \mathrm{g} / \mathrm{ml}$ streptomycin. Fspl-Cre mice (JAX) were mated with R26R $\mathrm{R}^{\text {tdTomato }}$ mice (JAX) to generate mice with specific expression of tdTomato in MEFs, which were used for lineage tracing experiments. OG2 mice (JAX) were mated with C57BL/6 to generate OG2 MEFs carrying Oct4::GFP reporter. Mouse TTFs were isolated from C57BL/6 neonate on day 2. Tail tips were cut into pieces and then dispersed on gelatin-coated $10 \mathrm{~cm}$ culture dish containing $2 \mathrm{ml}$ fibroblast growth medium, and additional $8 \mathrm{ml}$ medium was supplemented on the next day.

\section{Generation of CiCMs}

MEFs or TTFs were seeded onto six-well plates (coated with 1:100 Matrigel from BD Biosciences for $1 \mathrm{~h}$ at room temperature) at a density of 50000 cells per well and cultured in fibroblast growth medium. After $24 \mathrm{~h}$, the medium was replaced with CRM plus various compound combinations, such as CRFVPT. CRM is composed of knockout DMEM (Gibco), 15\% FBS, and 5\% KSR (Gibco), 0.5\% N2 (Gibco), 2\% B27 (Gibco), 1\% Glutamax, 1\% NEAA, $0.1 \mathrm{mM} \beta$-mercaptoethanol (Gibco), $50 \mu \mathrm{g} / \mathrm{ml} 2$-phospho-L-ascorbic acid (vitamin C, Sigma), 100 units/ml penicillin and $100 \mu \mathrm{g} / \mathrm{ml}$ streptomycin. CRFVPT cocktail consists of 10 $\mu \mathrm{M}$ CHIR99021 (C); $10 \mu \mathrm{M}$ RepSox (R); $50 \mu \mathrm{M}$ Forskolin (F); $0.5 \mathrm{mM}$ VPA (V); $5 \mu \mathrm{M}$ Parnate, (P); $1 \mu \mathrm{M}$ TTNPB (T). CRM containing chemical compounds was changed every 4 days. At the second stage of induction (day 16 for MEF, day 20 for TTF), cells were cultured in CMM for various days. CMM is composed of DMEM medium with 15\% FBS, $2 \mathrm{i}(3 \mu \mathrm{M}$ CHIR99021 and $1 \mu \mathrm{M}$ PD0325901), 1000 units $/ \mathrm{ml} \mathrm{LIF,} 50 \mu \mathrm{g} / \mathrm{ml}$ vitamin C, and $1 \mu \mathrm{g} / \mathrm{ml}$ insulin (Sigma). The following growth factors were also tested in CMM for the generation of TTF-derived CiCMs: T $\beta-4(100 \mathrm{ng} / \mathrm{ml}$, PeproTech), GDF-11 (100 ng/ml, PeproTech), G-CSF (20 ng/ml, R\&D systems), NRG1- $\beta 1$ (100 ng/ml, R\&D systems).

\section{Generation of smooth muscle cells and endothelial cells}

Smooth muscle cells and endothelial cells were differentiated following the same protocol for cardiac reprogramming, except after day 20, CMM was replaced with smooth muscle growth medium containing 50\% IMDM (Gibco) plus 50\% F-12 (Gibco), supplemented with insulin $(7 \mu \mathrm{g} / \mathrm{ml})$, monothioglycerol $(450 \mu \mathrm{M}$, Sigma), bovine serum albumin (BSA; fraction V, $5 \mathrm{mg} / \mathrm{ml}$, Gibco) and PDGF-BB (10 ng/ml, R\&D Systems), or the endothelial cell growth medium EGM2 (Lonza) with VEGFA (10 ng/ml, R\&D Systems) for another two weeks.

\section{Immunofluorescent staining}

Cells were fixed in 4\% PFA at room temperature for $30 \mathrm{~min}$ and washed with PBS twice. After permeabilizing with $0.3 \%$ Triton X-100 for $20 \mathrm{~min}$, the cells was treated with 5\% BSA for 1-2 $\mathrm{h}$, then incubated with various primary antibodies at $4{ }^{\circ} \mathrm{C}$ overnight. After thorough washing, secondary antibodies conjugated with Alexa Fluor 555 or Alexa Fluor 488 were used. Nuclei were visualized with Hochest $33342(10 \mu \mathrm{g} / \mathrm{ml})$. Images were captured with an Olympus IX71 inverted fluorescent microscope. Antibodies used in this study are as following: cTNT (ab10214, Abcam), GATA4 (MABE477, Millipore and SC-25310 Santa Cruz), NKX2.5 (8792, CST \& Ab35842, Abcam), cTNI (ab47003, Abcam), $\alpha$-actinin (A7811, Sigma), Mef2c (5030S, CST), $\alpha$-MHC (ab15, Abcam), Sca-1 (17-5981-81, eBioscience), $\alpha$-SMA (A2547, Sigma), PECAM (SC-1506, Santa Cruz), Cnn2 (SC-16607, Santa Cruz), VE-cadherin (SC-9989, Santa Cruz), MLC2v (ab79935, Abcam), MLC2a (311011, Synaptic systems), and HCN4 (Ab69054, Abcam).

\section{Real-time PCR}

Total mRNA was isolated using Trizol (Invitrogen) and $2 \mu \mathrm{g}$ 
RNA was used to synthesize cDNA using the PrimeScript RTreagent kit (Takara, DRR037A) according to the manufacturer's protocol. Real-time PCR was performed using FastStart Universal Probe Master Mix (Roche) and analyzed with a Stratagene Mx 3000P thermal cycler. Real-Time PCR primer sequences are listed in Supplementary information, Table S1.

\section{FACS Analyses}

For FACS analyses, cells were treated with collagenase II (1 $\mathrm{mg} / \mathrm{ml})$ and trypsin $(0.25 \%)$. The single cell suspensions were then treated with fixation/permeabilization diluent (BD bioscience) at 4 ${ }^{\circ} \mathrm{C}$ for $20 \mathrm{~min}$, and stained with anti- $\alpha$-actinin or anti- $\alpha$-MHC antibodies, followed by secondary antibodies conjugated with APC or Alexa 488. Cells were then analyzed with a Guava flow cytometer (Millipore) and the data were collected with the FlowJo software.

\section{Intracellular $\mathrm{Ca}^{2+}$ measurement}

To record calcium transients, the CiCMs were incubated with 2 $\mu \mathrm{M}$ Fluo-4 AM in HEPES buffered saline solution $(140 \mathrm{mM} \mathrm{NaCl}$, $2.8 \mathrm{mM} \mathrm{KCl}, 2 \mathrm{mM} \mathrm{CaCl}_{2}, 2 \mathrm{mM} \mathrm{MgCl} 2,10 \mathrm{mM}$ glucose, and 10 $\mathrm{mM}$ HEPES, $\mathrm{pH} 7.4$ ) at $37^{\circ} \mathrm{C}$ for 20 min to allow de-esterification of the dye that had penetrated the cell membrane. After removing excess dye in the buffer, spontaneous $\mathrm{Ca}^{2+}$ transients were recorded at $37{ }^{\circ} \mathrm{C}$ using an Olympus IX81 motorized inverted fluorescence microscope and a time-lapse recording system (Xcellence). At least 8 fields in each dish were recorded and the recording lasted for at least $1 \mathrm{~min}$ for each field. Isoproterenol (Iso, $1 \mu \mathrm{M}$ ) or carbachol (Cch, $5 \mu \mathrm{M})$ was applied to the cells before the recording for 2 or $5 \mathrm{~min}$, respectively.

\section{Patch clamp recording}

Patch clamp recording was performed in a temperature-controlled room at $\sim 25^{\circ} \mathrm{C}$. The Giga-Ohm seal was achieved under the voltage-clamp mode and the APs were recorded under the current-clamp configuration using an Axopatch-200B amplifier (Molecular Devices). The pipette solution contained $145 \mathrm{mM} \mathrm{KCl}$, $1 \mathrm{mM} \mathrm{MgCl}_{2}, 5 \mathrm{mM}$ EGTA, $10 \mathrm{mM}$ HEPES, and $10 \mathrm{mM} \mathrm{Na} \mathrm{ATP}_{2}$ (pH 7.3 with $\mathrm{KOH}$ ). During the recording, constant perfusion of extracellular solution was maintained using a BPS perfusion system (ALA scientific Instruments). Extracellular solution contained $140 \mathrm{mM} \mathrm{NaCl}, 3 \mathrm{mM} \mathrm{KCl}, 2 \mathrm{mM} \mathrm{CaCl}_{2}, 1.5 \mathrm{mM} \mathrm{MgCl}_{2}$, $10 \mathrm{mM}$ HEPES, and $10 \mathrm{mM}$ glucose (pH 7.4 with $\mathrm{NaOH})$. Signals were filtered at $1 \mathrm{kHz}$, and digitized using a DigiData 1440 with pClamp9.2 software (Molecular Devices).

\section{Microarray analysis}

Gene expression microarray analyses of MEFs, MEF-CiCMs (beating colonies were picked at day 24), and cardiomyocytes were performed using Affymetrix GeneChip Mouse Genome 430 2.0 arrays in triplicate from independent biological samples. Data were analyzed using the GeneChip Scanner 3000 and Commad Console Software 3.1 with default setting. Raw data were normalized by MAS 5.0 algorithm, Gene Spring Software 11.0. Genes displaying 5 -fold or greater changes $(P<0.05, t$-test) in expression level between MEFs and MEF-CiCMs were selected to generate the heatmap and for GO term enrichment analysis (DAVID 6.7 software) [39]. The microarray data are available at the NCBI Gene Expression Omnibus with accession number GSE69924 (http://www.ncbi.nlm.nih.gov/geo/info/linking.html).

\section{Statistic analysis}

Values are reported as the means \pm SEM. $P$-values were calculated by Student's $t$-test, $P<0.05$ was considered statistically significant. All graphs were plotted with GraphPad Prism software.

\section{Acknowledgments}

We would like to thank Drs Huangtian Yang and Zhaobin Gao for their advice and technical support on electrophysiology study. Project was supported by grants from Chinese Academy of Sciences (XDA01040301), Ministry of Science and Technology of China (2015CB964503), and the National Natural Science Foundation of China (81425024, 31371511).

\section{References}

1 Xin M, Olson EN, Bassel-Duby R. Mending broken hearts: cardiac development as a basis for adult heart regeneration and repair. Nat Rev Mol Cell Biol 2013; 14:529-541.

2 Leask A. Potential therapeutic targets for cardiac fibrosis: TGFbeta, angiotensin, endothelin, CCN2, and PDGF, partners in fibroblast activation. Circ Res 2010; 106:1675-1680.

3 Tongers J, Losordo DW, Landmesser U. Stem and progenitor cell-based therapy in ischaemic heart disease: promise, uncertainties, and challenges. Eur Heart J 2011; 32:1197-1206.

4 Hsiao LC, Carr C, Chang KC, Lin SZ, Clarke K. Stem cellbased therapy for ischemic heart disease. Cell Transplant 2013; 22:663-675.

5 Xu J, Du Y, Deng H. Direct lineage reprogramming: strategies, mechanisms, and applications. Cell Stem Cell 2015; 16:119-134.

6 Ieda M, Fu JD, Delgado-Olguin P, et al. Direct reprogramming of fibroblasts into functional cardiomyocytes by defined factors. Cell 2010; 142:375-386.

7 Qian L, Huang Y, Spencer CI, et al. In vivo reprogramming of murine cardiac fibroblasts into induced cardiomyocytes. $\mathrm{Na}$ ture 2012; 485:593-598.

8 Song KH, Nam YJ, Luo X, et al. Heart repair by reprogramming non-myocytes with cardiac transcription factors. Nature 2012; 485:599-604.

9 Jayawardena TM, Egemnazarov B, Finch EA, et al. MicroRNA-mediated in vitro and in vivo direct reprogramming of cardiac fibroblasts to cardiomyocytes. Circ Res 2012; 110:1465-1473.

10 Efe JA, Hilcove S, Kim J, et al. Conversion of mouse fibroblasts into cardiomyocytes using a direct reprogramming strategy. Nat Cell Biol 2011; 13:215-U261.

11 Wang H, Cao N, Spencer CI, et al. Small molecules enable cardiac reprogramming of mouse fibroblasts with a single factor, Oct4. Cell Rep 2014; 6:951-960.

12 Hou P, Li Y, Zhang X, et al. Pluripotent stem cells induced from mouse somatic cells by small-molecule compounds. Science 2013; 341:651-654.

13 Long Y, Wang M, Gu H, Xie X. Bromodeoxyuridine promotes full-chemical induction of mouse pluripotent stem cells. Cell Res 2015 Aug 7. doi: 10.1038/cr.2015.96.

14 Cheng L, Hu WX, Qiu BL, et al. Generation of neural progenitor cells by chemical cocktails and hypoxia. Cell Res 
2014; 24:665-679.

15 Kong YP, Carrion B, Singh RK, Putnam AJ. Matrix identity and tractional forces influence indirect cardiac reprogramming. Sci Rep 2013; 3:3474.

16 Mureli S, Gans CP, Bare DJ, Geenen DL, Kumar NM, Banach $\mathrm{K}$. Mesenchymal stem cells improve cardiac conduction by upregulation of connexin 43 through paracrine signaling. $\mathrm{Am}$ J Physiol Heart Circ Physiol 2013; 304:H600-H609.

17 Zouein FA, Kurdi M, Booz GW. LIF and the heart: just another brick in the wall? Eur Cytokine Netw 2013; 24:11-19.

18 Frias MA, Montessuit C. JAK-STAT signaling and myocardial glucose metabolism. JAKSTAT 2013; 2:e26458.

19 Kattman SJ, Witty AD, Gagliardi M, et al. Stage-specific optimization of activin/nodal and BMP signaling promotes cardiac differentiation of mouse and human pluripotent stem cell lines. Cell Stem Cell 2011; 8:228-240.

20 Odiete O, Hill MF, Sawyer DB. Neuregulin in cardiovascular development and disease. Circ Res 2012; 111:1376-1385.

21 Smart N, Bollini S, Dube KN, et al. De novo cardiomyocytes from within the activated adult heart after injury. Nature 2011; 474:640-U117.

22 Shimoji K, Yuasa S, Onizuka T, et al. G-CSF promotes the proliferation of developing cardiomyocytes in vivo and in derivation from ESCs and iPSCs. Cell Stem Cell 2010; 6:227-237.

23 Loffredo FS, Steinhauser ML, Jay SM, et al. Growth differentiation factor 11 is a circulating factor that reverses age-related cardiac hypertrophy. Cell 2013; 153:828-839.

24 Lieu DK, Liu J, Siu CW, et al. Absence of transverse tubules contributes to non-uniform $\mathrm{Ca} 2+$ wavefronts in mouse and human embryonic stem cell-derived cardiomyocytes. Stem Cells Dev 2009; 18:1493-1500.

25 Gromada J, Jorgensen TD, Dissing S. The release of intracellular $\mathrm{Ca} 2+$ in lacrimal acinar cells by alpha-, beta-adrenergic and muscarinic cholinergic stimulation: the roles of inositol triphosphate and cyclic ADP-ribose. Pflugers Arch 1995; 429:751-761.

26 Reinecke H, MacDonald GH, Hauschka SD, Murry CE. Electromechanical coupling between skeletal and cardiac muscle: implications for infarct repair. J Cell Biol 2000; 149:731-740.

27 Hescheler J, Fleischmann BK, Lentini S, et al. Embryonic stem cells: a model to study structural and functional properties in cardiomyogenesis. Cardiovasc Res 1997; 36:149-162.

28 Stieber J, Herrmann S, Feil S, et al. The hyperpolarization-activated channel HCN4 is required for the generation of pacemaker action potentials in the embryonic heart. Proc Natl Acad Sci USA 2003; 100:15235-15240.

29 Bhowmick NA, Chytil A, Plieth D, et al. TGF-beta signaling in fibroblasts modulates the oncogenic potential of adjacent epithelia. Science 2004; 303:848-851.

30 Zaffran S, Frasch M. Early signals in cardiac development. Circ Res 2002; 91:457-469.

31 Zhou B, Ma Q, Rajagopal S, et al. Epicardial progenitors contribute to the cardiomyocyte lineage in the developing heart. Nature 2008; 454:109-113.

32 Gonzales C, Ullrich ND, Gerber S, Berthonneche C, Niggli E, Pedrazzini T. Isolation of cardiovascular precursor cells from the human fetal heart. Tissue Eng Part A 2012; 18:198-207.

33 Chien KR, Domian IJ, Parker KK. Cardiogenesis and the complex biology of regenerative cardiovascular medicine. Science 2008; 322:1494-1497.

34 Mauritz C, Martens A, Rojas SV, et al. Induced pluripotent stem cell (iPSC)-derived Flk-1 progenitor cells engraft, differentiate, and improve heart function in a mouse model of acute myocardial infarction. Eur Heart J 2011; 32:2634-2641.

35 Lian X, Hsiao C, Wilson G, et al. Robust cardiomyocyte differentiation from human pluripotent stem cells via temporal modulation of canonical Wnt signaling. Proc Natl Acad Sci USA 2012; 109:E1848-1857.

36 Marucci L, Pedone E, Di Vicino U, Sanuy-Escribano B, Isalan M, Cosma MP. Beta-catenin fluctuates in mouse ESCs and is essential for nanog-mediated reprogramming of somatic cells to pluripotency. Cell Rep 2014; 8:1686-1696.

37 Matsumura K, Mayama T, Lin H, Sakamoto Y, Ogawa K, Imanaga I. Effects of cyclic AMP on the function of the cardiac gap junction during hypoxia. Exp Clin Cardiol 2006; 11:286-293.

38 Keravis T, Lugnier C. Cyclic nucleotide phosphodiesterase (PDE) isozymes as targets of the intracellular signalling network: benefits of PDE inhibitors in various diseases and perspectives for future therapeutic developments. $\mathrm{Br} J$ Pharmacol 2012; 165:1288-1305.

39 Huang da W, Sherman BT, Lempicki RA. Systematic and integrative analysis of large gene lists using DAVID bioinformatics resources. Nat Protoc 2009; 4:44-57.

(Supplementary information is linked to the online version of the paper on the Cell Research website.)

(c) (i) () $\odot$ This work is licensed under a Creative Commons Attribution-NonCommercial-NoDerivs 4.0 Unported License. The images or other third party material in this article are included in the article's Creative Commons license, unless indicated otherwise in the credit line; if thematerial is not included under the Creative Commons license, users will need to obtain permission from the license holder to reproduce the material. To view a copy of this license, visit http://creativecommons.org/licenses/by-nc-nd/4.0/ 